\title{
Geospatial Analysis of Ambulance Station Coverage of the Acute Coronary Syndrome Incidents in Semey, Kazakhstan
}

\author{
Askhat Shaltynov ${ }^{1}$, Askar Abiltaev $^{2}$, Bakytzhan Konabekov ${ }^{1}$, Ulzhan Jamedinova $^{2}$, Daulet Aldyngurov ${ }^{3}$, Aigul Utegenova $^{3}$, \\ Ayan Myssayev ${ }^{4 *}$
}

${ }^{1}$ Department of Public Health, NCJSC "Semey Medical University", Semey, Kazakhstan; 'Department of Epidemiology and Biostatistics, NCJSC "Semey Medical University", Semey, Kazakhstan; ${ }^{3}$ Department of Science and Innovation, Non-profit JSC "Astana Medical University", Semey, Kazakhstan; ${ }^{4}$ Department of Innovative Education, NCJSC "Semey Medical University", Semey, Kazakhstan

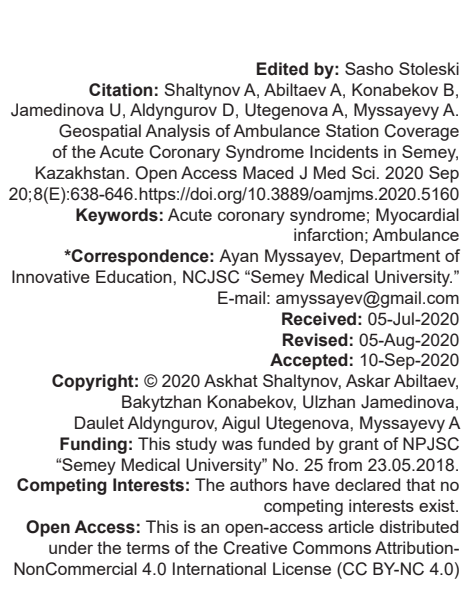

\section{Background}

One of the main causes of death is cardiovascular diseases. According estimation 17.8 million people died from cardiovascular diseases in 2017 globally [1]. In 2018, cardiovascular diseases brouht about $167.28 / 100,000$ deaths and were the leading cause of death in Kazakhstan [2]. Among cardiovascular diseases ischemic heart disease is major cause of death [1]. In this paper, we discuss about ambulance care coverage for several conditions such as ST-elevation of myocardial infarction (STEMI), non-ST-elevation of myocardial infarction (NSTEMI), and unstable angina (UA), which fall under the umbrella term of ACS. Since these conditions can end up with cardiac arrest, they demand quick emergency care.

One of the important factors in diagnosing and treatment of STEMI is time, which plays crucial role in the outcome of patients [3]. The time includes time from the first symptom patient feels to the call to the emergency medical services, time from dispatchers receive the call to the arrival of ambulance to the scene, time from medical examination, and diagnosing on the scene and carrying the patient to hospital. The distance between ambulance location and the scene, day time, the development of urban transport system, weather conditions may have an impact on ambulance response delay [4], [5], [6], [7]. A study, which analyzed factors of ambulance delay in STEMI cases, confirmed the impact of distance on transportation time from an ambulance station to scene. In addition, age was a predictor associated with ambulance delay [8]. Thus, there are a lot of predictors, which affect time and should be considered to lessen negative outcome among patients with ACS.

Methods of geoinformation system are widely implemented in medicine for analyzing from geographical pattern of disease to hospital accessibility [9], [10], [11], [12]. 
Methods of geoinformation analysis allow to refer different data to the geographical location and to visualize them that provide more comprehensive analyzing. One of the such research, where GIS was used for analyzing accessibility to hospitals providing percutaneous coronary interventions $(\mathrm{PCl})$ in the scale of a whole country (Russia) [12]. The study shows that anapropriate logistics can worsen accessibility to the $\mathrm{PCl}$ hospitals and simple adding of medical facilities with $\mathrm{PCl}$ can improve the situation in the country. GIS and mathematical modeling can implemented for choosing an optimal treatment option of STEMI bases on location of a case and the travel time to a $\mathrm{PCl}$ hospital [13].

The problem of ambulance response time and appropriate locating of ambulance station remain important last decade [14], [15], [16], [17], [18], [19]. Furthermore, these concerning are supported by increasing ambulance demand [20], [21], [22]. Thus, the aim of the study is to investigate the coverage area of calls of ACS by ambulance stations in regard to the time using GIS-analyze.

\section{Methods}

This was descriptive study which contains secondary data from Semey ambulance service's database about all 1704 acute coronary syndrome (ACS) with and without elevation of ST segment emergency calls in Semey city (Kazakhstan) over the period from August 1, 2017 to May 30, 2018. According to ambulance service database ACS with ST segment elevation was defined as I21.1, 21.9, I22, I23.0, I23.2, I23.3, and I23.4 without ST segment elevation 120.0, 121.2, 121.4, and I24.9 codes of ICD-10 classification. This database has collected data including age, sex and social status of patient, address of call, time (time of receive call, ambulance departure time, ambulance arrival time, patient hospitalization time, and ambulance release time), ambulance substation, mileage of ambulance, and result of emergency call. Semey city is located in East Kazakhstan region and consist of right-bank and left-bank parts divided by Irtysh River (Figure 1). It has a population of 349,7 thousand and covers $210 \mathrm{~km}^{2}$. Main ambulance station, one ambulance substation and two main hospitals for ACS patients located on the right bank and one ambulance substation on the left bank.

Spatial Analyst and NetworkAnalyst Extensions of ArcGIS 10.7 (ESRI, CA, USA) were used to define high ACS density areas and find 10, 15, and $20 \mathrm{~min}$ time response areas. Kernel Density tool calculates a magnitude-per-unit area from point or polyline features using a kernel function to fit a smoothly tapered surface to each point or polyline. New Service Area tool creates a region that encompasses all accessible streets (that is, streets that are within specified impedance).

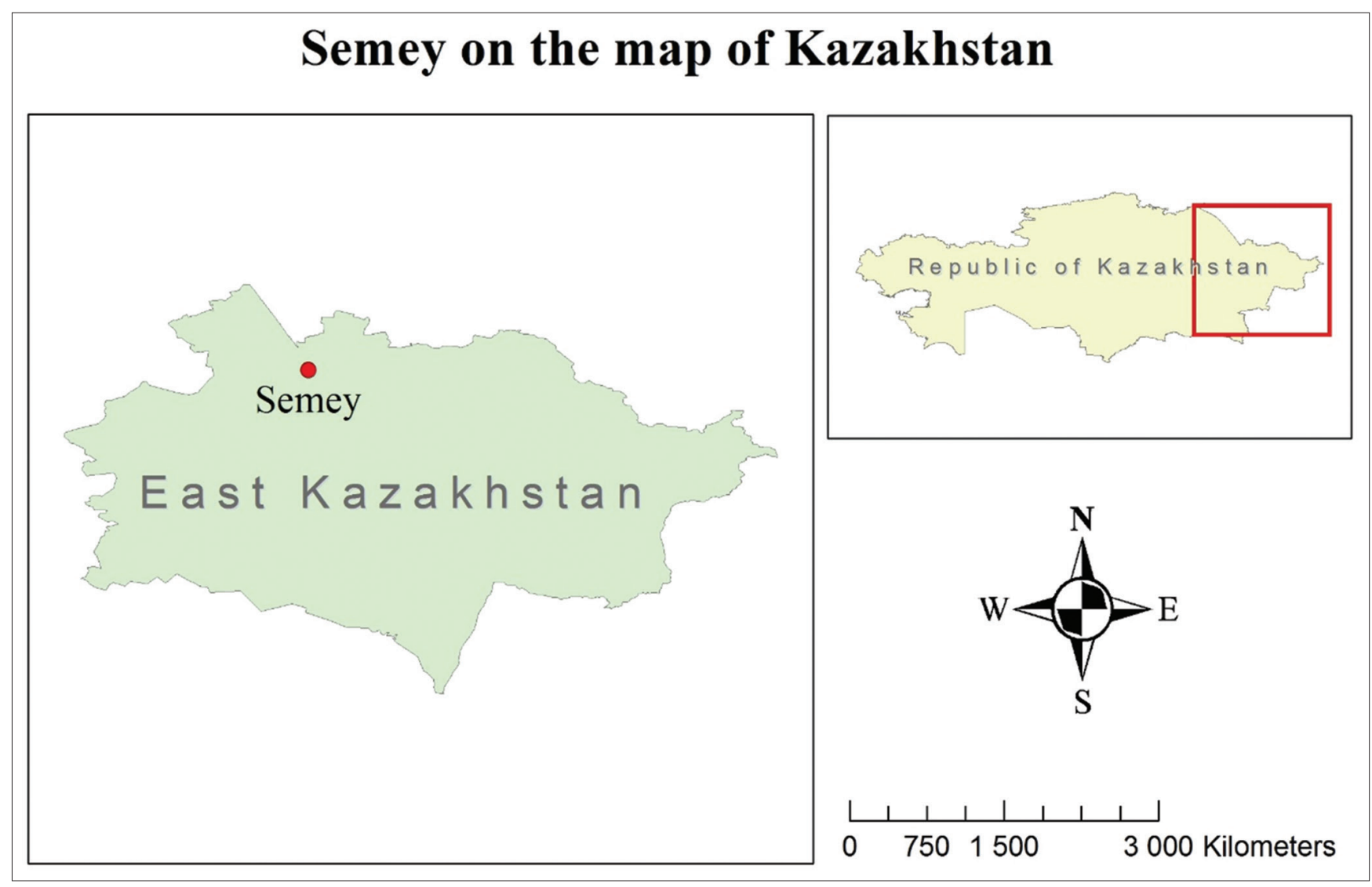

Figure 1: Geographical location of Semey in Kazakhstan 
ArgGIS Optimized Hot Spot Analysis and Optimized Outlier Analysis were performed to find significantly high areas of ACS.

Optimized Hot Spot Analysis executes the Hot Spot Analysis (Getis-Ord $\mathrm{Gi}^{*}$ ) tool using parameters derived from characteristics of your input data. This tool works by looking at each feature within the context of neighboring features. Optimized Outlier Analysis executes the Cluster and Outlier Analysis (Anselin Local Moran's I) tool using parameters derived from characteristics of your input data. The cluster/outlier type distinguishes between a statistically significant cluster of high values $(\mathrm{HH})$, cluster of low values (LL), and outlier in which a high value is surrounded primarily by low values $(\mathrm{HL})$, and outlier in which a low value is surrounded primarily by high values (LH). Statistical significance is set at the $95 \%$ confidence level.

Map of Semey city based on OpenStreetMaps geodata. Address of each ACS incident was geocoded with Yandex geocoder.

All descriptive statistics calculations were performed with R Studio software, version 1.1.463.

The study was approved by the Ethics Committee of Semey Medical University.

\section{Results}

Twenty cases excluded from final sample due to did not have information about the address of the call, 284 calls related to transporting patients from one hospital to another, and 186 calls were not geocoded correctly. For this reason, only 1214 from 1704 incidents of ACS selected for statistical and GIS analysis (Figure 2).

As shown in Figure 2, call points were usually located in built-up parts of the city. In addition, Semey has two bridges that lead to severe problems with traffic jams. This factor complicates driving in the city and should be taken into account by ambulance routing.

Table 1 provides information that among all patients there were more men; moreover, men were younger than women.

Table 1: Gender and age characteristics of ACS patients

\begin{tabular}{lll}
\hline Gender, $\mathrm{n}(\%)$ & & \\
\hline Males & Females & Total \\
\hline $706(58,2)$ & $508(41,8)$ & $1214(100)$ \\
Age, Me (Q1, Q3) & $70(61,78)$ & $64(56,75)$ \\
$61(53,70)$ &
\end{tabular}

More than half of the patients were pensioners with unstable angina, $1 \%$ of patients died, $17.5 \%$ of patients did not need transportation for specialized care or hospitalization (Table 2).

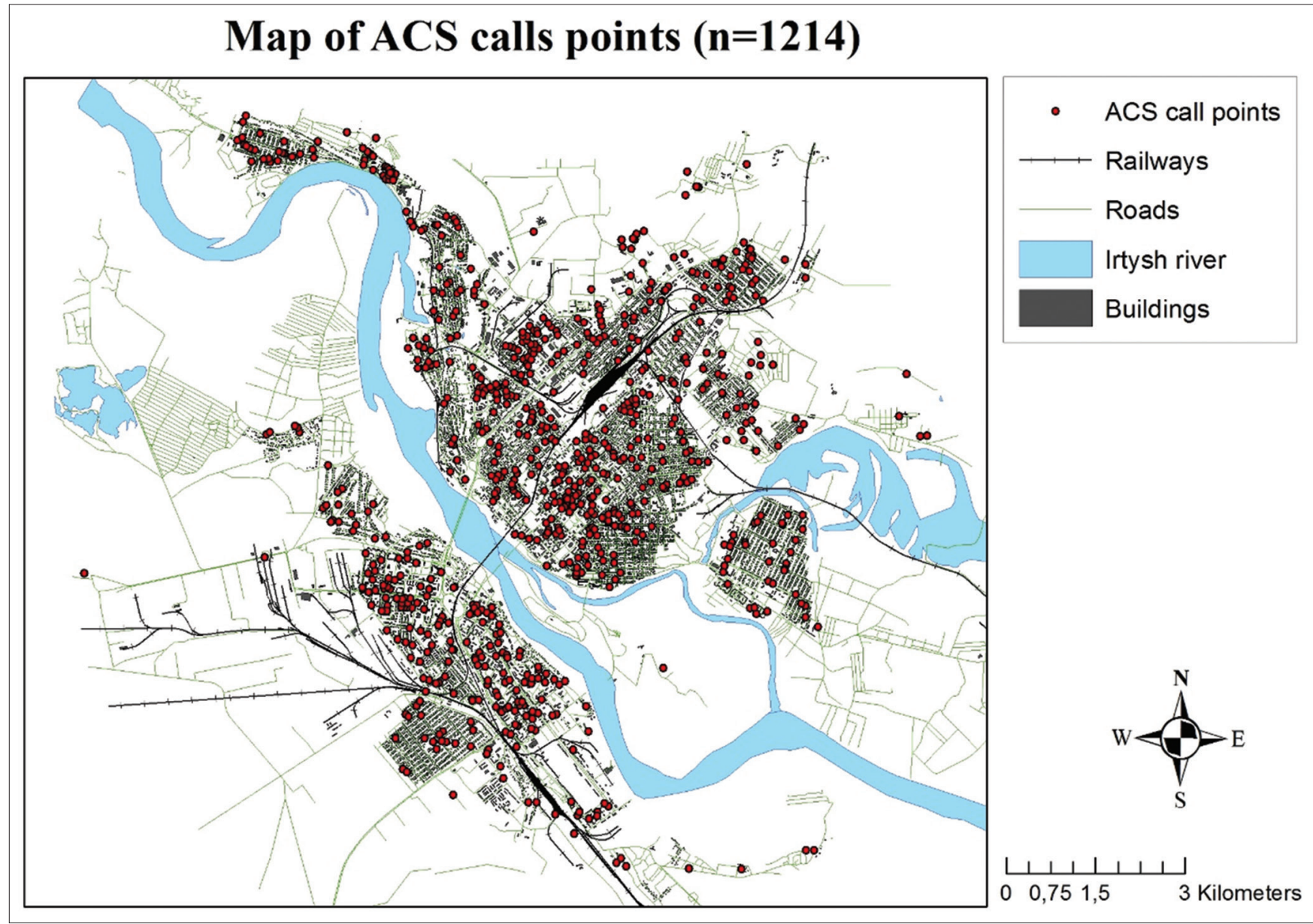

Figure 2: The geographical distribution of ACS cases 
Most often, the distance to the patient for ambulances was from 7 to $15 \mathrm{~km}$ (Table 3 ). For most calls, the response time was $<10 \mathrm{~min}$, which is the recommended national standard for emergency care (Table 3).

Table 2: Social-economic status (SES), diagnosis, and call result of ACS patients

\begin{tabular}{llll}
\hline & SES & $\mathrm{n}$ & $\%$ \\
\hline 1 & Pensioner & 695 & 57.2 \\
2 & Working & 210 & 17.3 \\
3 & Unemployed & 131 & 10.8 \\
4 & Other & 116 & 9.6 \\
5 & Not Available data & 47 & 3.9 \\
6 & Temporarily unemployed & 11 & 0.9 \\
7 & Preschool child & 1 & 0.1 \\
8 & Student & 1 & 0.1 \\
9 & Serviceman & 1 & 0.1 \\
10 & Homeless & 1 & 0.1 \\
& Total & 1214 & 100 \\
\hline & Diagnosis & $\mathrm{n}$ & $\%$ \\
\hline 1 & I20.0 - Unstable angina & 720 & 59.3 \\
2 & I21.9 - Acute myocardial infarction, unspecified & 252 & 20.8 \\
3 & I21.2 - ST elevation (STEMI) myocardial infarction of other sites & 131 & 10.8 \\
4 & I21.4 - Non-ST elevation (NSTEMI) myocardial infarction & 23 & 1.9 \\
5 & I21.1 - ST elevation (STEMI) myocardial infarction of inferior wall & 11 & 0.9 \\
6 & I24.9 - Acute ischemic heart disease, unspecified & 50 & 4.1 \\
7 & I22- Subsequent ST elevation (STEMI) and non-ST elevation & 16 & 1.3 \\
& (NSTEMI) myocardial infarction & & \\
8 & I23.3 - Rupture of cardiac wall without hemopericardium as current & 4 & 0.3 \\
& complication following acute myocardial infarction & & \\
9 & I23.4 - Rupture of chordae tendineae as current complication & 4 & 0.3 \\
& following acute myocardial infarction & & \\
10 & I23.2 - Ventricular septal defect as current complication following & 2 & 0.2 \\
& acute myocardial infarction & & \\
11 & I23.0 - Hemopericardium as current complication following acute & 1 & 0.1 \\
& myocardial infarction & 1214 & 100 \\
\hline & Total & $\mathrm{n}$ & $\%$ \\
\hline & Result of call & & \\
\hline & &
\end{tabular}

\begin{tabular}{llll}
\hline 1 & Delivered for Special Assistance & & \\
2 & Delivered to hospitalization & 533 & 43.9 \\
3 & Left in place & 444 & 36.6 \\
4 & Transferred to another ambulance brigade & 213 & 17.5 \\
5 & Death in the presence of the ambulance brigade & 10 & 0.8 \\
6 & Death before arrival & 7 & 0.6 \\
7 & Delivered home & 5 & 0.4 \\
8 & Not correct coded & 1 & 0.1 \\
& Total & 1 & 0.1 \\
& & 1214 & 100
\end{tabular}

Figure 3 shows a map of a smoothed surface representing the kernel density of ACS. Density zones were divided into seven categories from white (from 0 to 3.4 cases $/ \mathrm{km}^{2}$ ) to red (from 59.9 to $86.1 \mathrm{cases} / \mathrm{km}^{2}$ ). The largest high-density area of ACS cases was located in central part of the city on right-bank of the river. The areas of high-rise buildings on the left bank of the river were also areas of high density.

Optimized Hot Spot Analysis was identifies statistically significant spatial clusters of high values (hot spots), neutral, and low values (cold spots) with $90 \%, 95 \%$, and $99 \%$ confidence level (Figure 4). Location of Hot spots of ACS cases was identical to a large area with high-rise buildings in the city center as in the assessment of kernel density estimation.

Figure 5 provides information not only about clusters but also the assessment of objects within these clusters. A High-High cluster (Red) means that the value of the index of the object is higher than that of other objects; the value in the neighborhood is higher than the values in the other neighborhoods. Low-High

\section{Kernel density of ACS calls points (abs n per 1 square kilometer)}

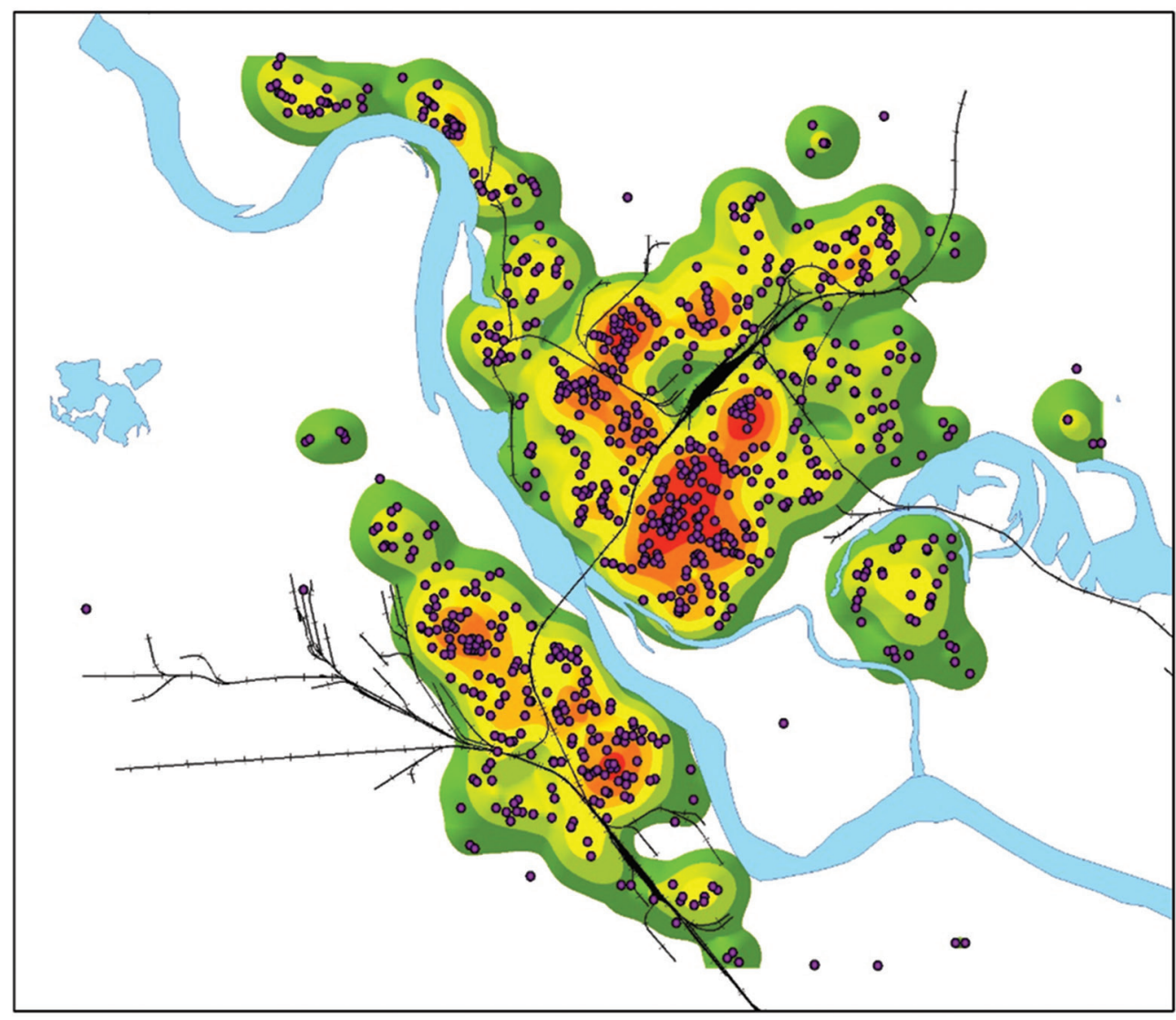

- ACS call points

Railways

Irtysh river

Kernel density

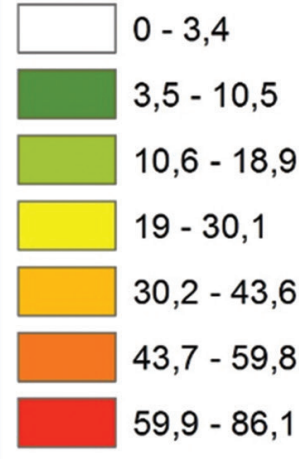

Figure 3: The map of density of ACS cases 

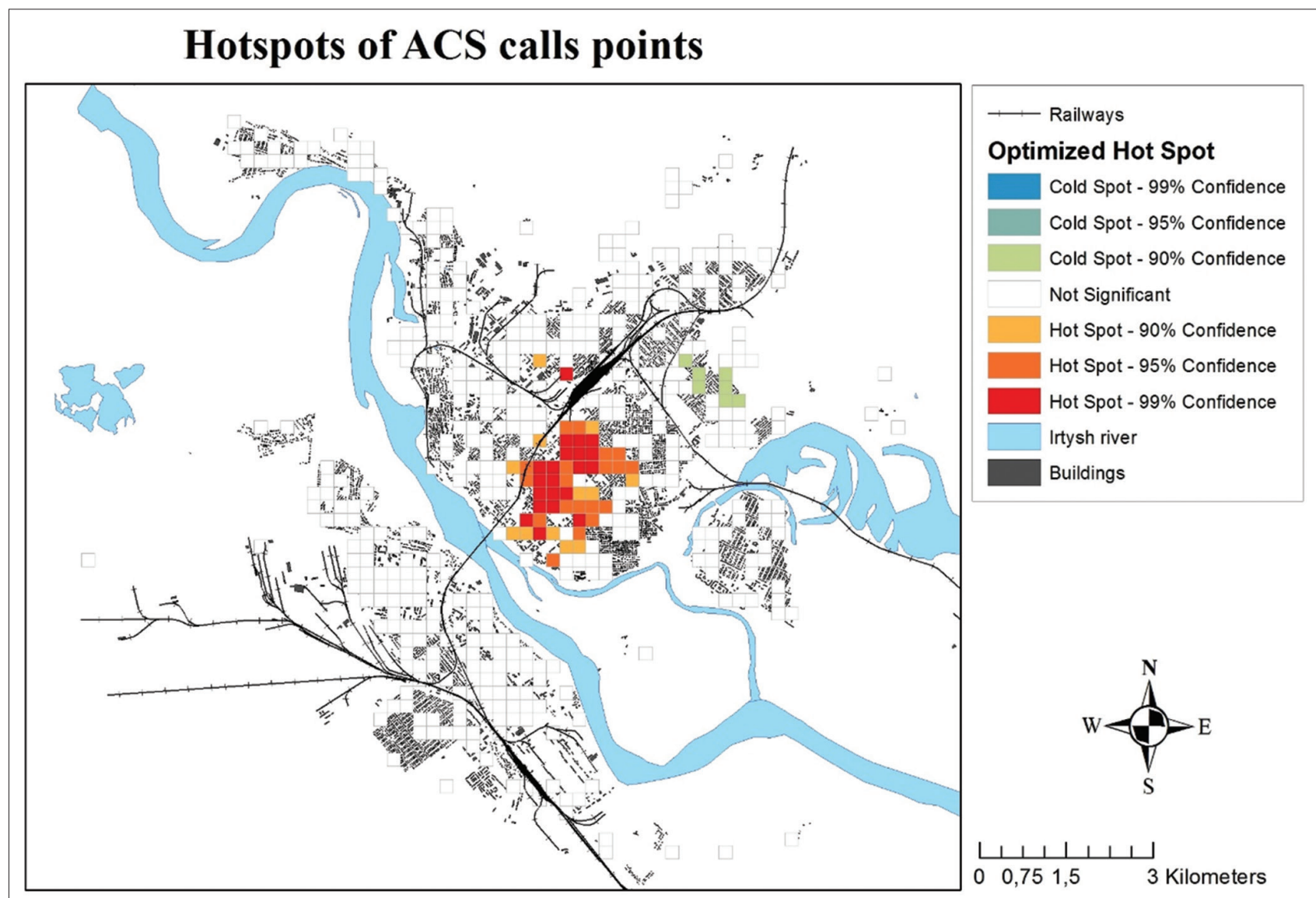

Figure 4: Hot spot map of ACS cases

\section{Clusters and outliers of ACS calls points}
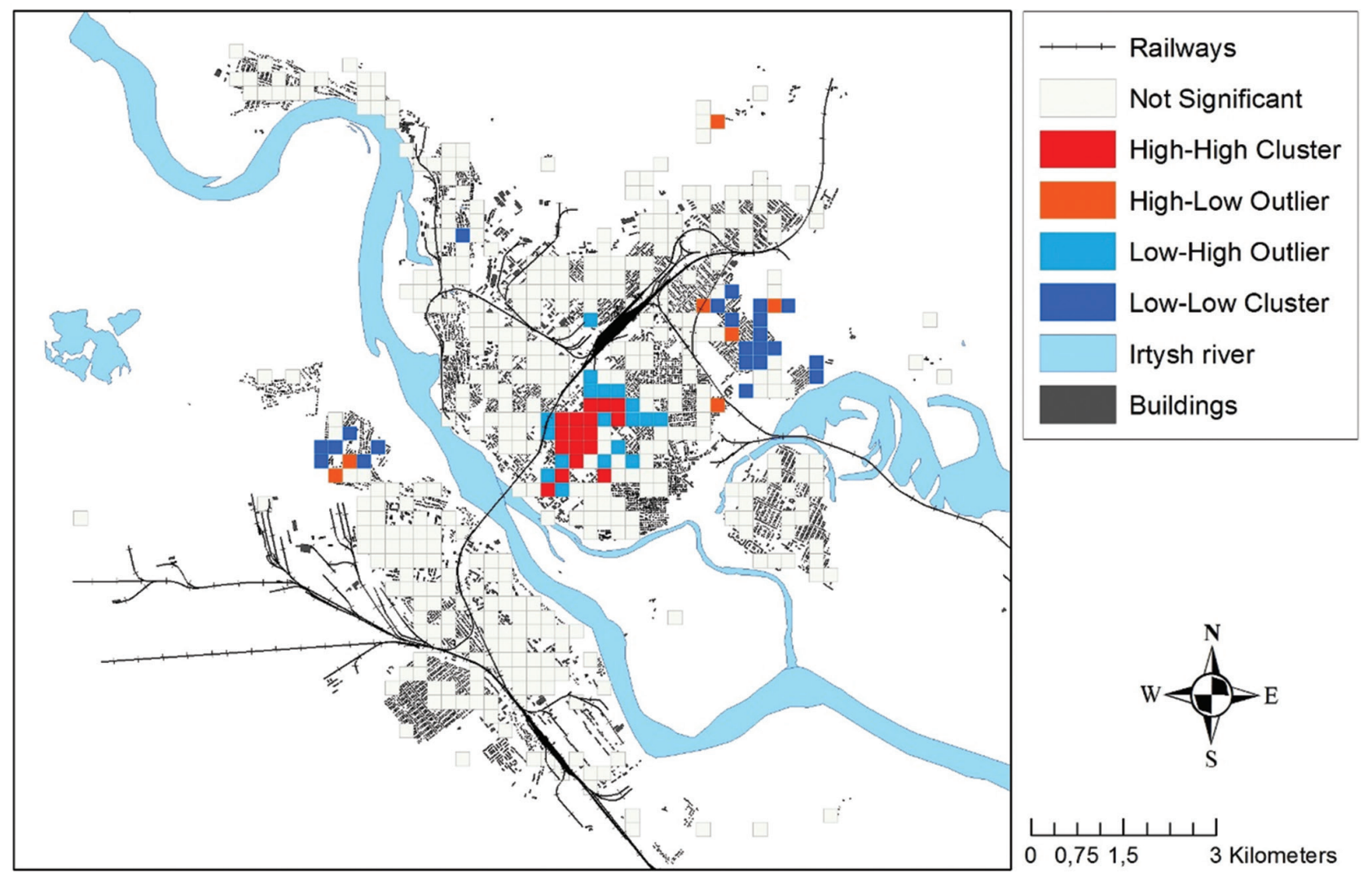

Figure 5: The map of clusters and outliers of ACS incidents 
outlier (Azure) means that the value of the object is lower than other objects; the value in the neighborhood is higher than the values in the rest of the neighborhood. Low-Low cluster (Blue) means that the value of the index of the object is lower than that of other objects; the value in the neighborhood is lower than the values in the rest of the neighborhood. High-Low outlier (Orange) means that the value of the object is higher than other objects; the value in the neighborhood is lower than the values in the rest of the neighborhood. High-High clusters and Low-High outliers were located in city center too.

\section{Table 3: Average ambulance mileage and average response} time

\begin{tabular}{ll}
\hline Ambulance response characteristics & Me (Q1, Q3) \\
\hline Average ambulance mileage $(\mathrm{km})$ & $11(7,15)$ \\
Average response time (minutes) & $9(7,10)$ \\
\hline
\end{tabular}

Results of Service Area estimation of Network Analyst Extension provide us picture of the accessibility zones on city roads for ambulances leaving ambulance stations at an average speed of $50 \mathrm{~km} / \mathrm{h}$ (Figure 6). Three ambulance stations cover high-density areas, Hot Spots, and High-High clusters with $10 \mathrm{~min}$, other residential buildings with $15 \mathrm{~min}$, a suburban area in the north-west of the city is located in a 20 -min accessibility zone.

\section{Discussion}

Ambulance in Kazakhstan is defined as a vital service and is included in the package of guaranteed volume of medical services covered by the state and is free for all citizens [23].

The emergency care system in Kazakhstan is based on the Soviet ambulance system with the provision of first aid emergency aid through ambulance stations. Ambulance stations work $24 \mathrm{~h}$ a day. Ambulance stations are staffed with ambulance car teams consisting of a driver, a doctor, a "feldsher" and sometimes cardiologist. At the place of the call, the doctor, depending on the patient's condition, and decides to leave him at home or parient should be taken to the hospital for specialized medical care. Information on the administered treatment is directed to patient's primary care institution. Usually, emergency care systems are established according to planning parameters such as population coverage and travel times [24], [25].

Semey city ambulance station provides medical care to more than 100,000 thousand people a year and it serves the territory of the Semey region of East Kazakhstan, with a radius of $80 \mathrm{~km}$, which includes nearby villages [26].

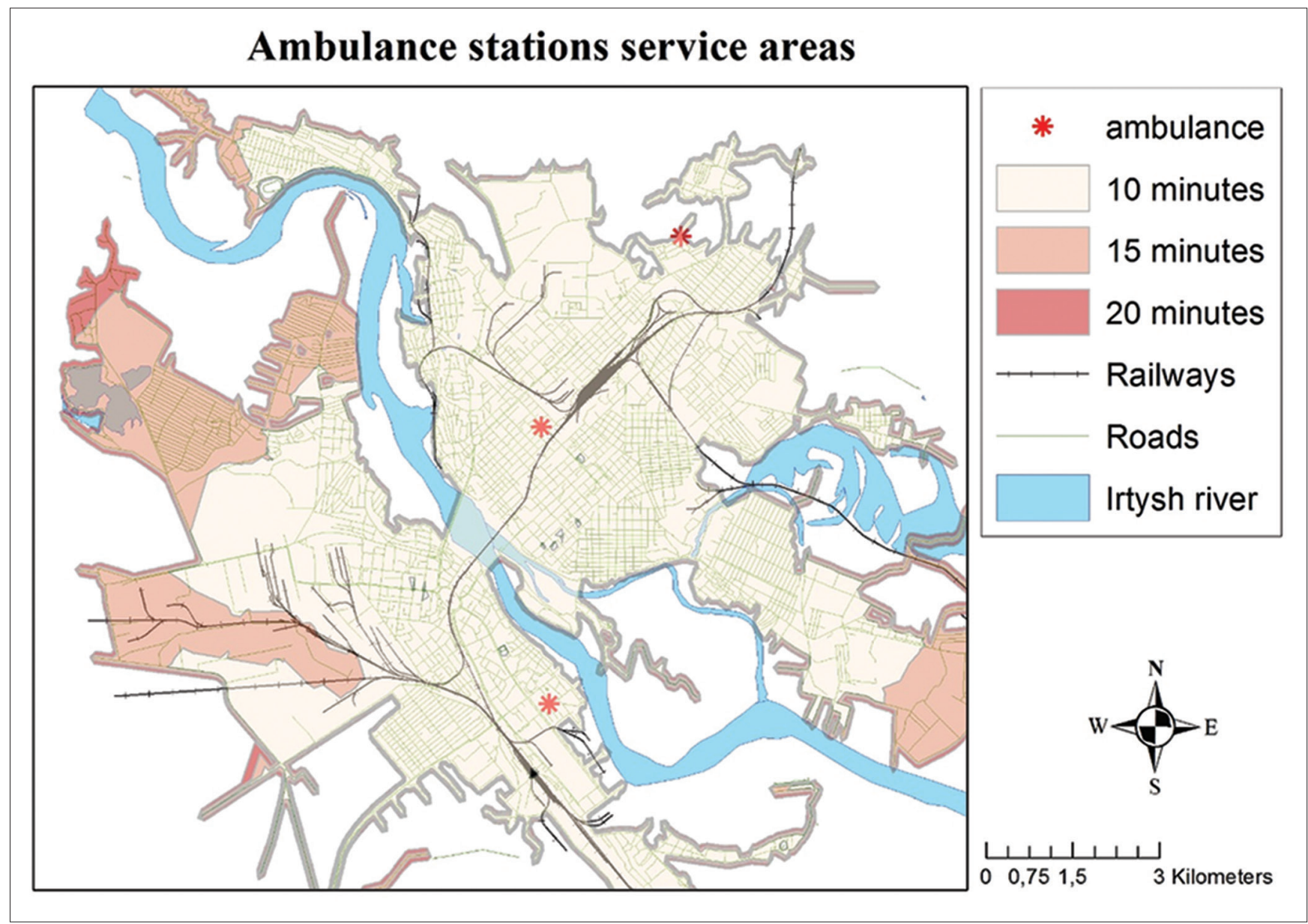

Figure 6: The map of ambulance service area 
To the best of our knowledge, it is the first study of ambulance coverage zone depending on time by using GIS-analyze in Kazakhstan.

The study reveals that in spite of locating only one ambulance station on the left bank of city, the locations of ambulance stations of Semey city allow to cover the bulk of area of the city within 10 min, which includes hotspots of ACS. The result consists with the findings of ambulance response time. However, there are some regions, which do not fall in 10-min coverage zone. In the previous study related to the ambulance station coverage area of Samsun city showed that ambulance stations are within $10-$ min distance of $99.0 \%$ of calls [27].

In our study, we use service area analysis, which allow to analyze all areas of the city. In the Turkish research, authors used buffer analysis to assess ambulance coverage zone. This method displays the overlapping zones, but it does not allow to assess accesses to areas which do not fall within buffer zone [27].

Furthermore, we map the emergency calls of ACS, using their coordinates, which allows to reveal the hotspots of emergency calls. In our research, the location of the hotspots was within the location of high-raised building districts. This approach can be used in planning emergency medical service to locate an ambulance station with regarding the most call density areas. Ambulance stations can be reallocated with regarding the need [28]. Gonzalez et al. used GIS for analyzing traffic collisions and to locate ambulance stations. The findings evidence the decrease of ambulance response time. Using a model Dibene et al. found that rearranging locations of ambulance stations could improve ambulance response time [29]. Other solution of such problem and meet the ART requirements can be the use of a predicting model. It is more sophisticated approach, which can take into consideration seasonal, week, day demand and also such factors as weather and traffic. Chen et al. used models combining with GIS to predict demand of emergency medical care [30]. Researchers suggest to use the predicting models to situate in advance ambulance cars in the areas with high demand. However, the predicting models and dynamic approach of locating ambulance cars can face various obstacles, because every city has its unique features, starting from geography till infrastructure and demography.

The ambulance response time is critical in providing care for urgent cases such as ACS. The decrease of ambulance responses time benefit in better clinical outcome as well as from economic point of view [31]. Moreover, it is need to take into account future development of a city to meet the requirement on ambulance response time. Using GIS to relocate of ambulance stations can improve ambulance response time without supplementary cost [19], [28].

In our study, we have analyzed incidents of ACS and ambulance station coverage. However, we have not studied the time, which takes from scene to hospital. Semey city has two hospitals: University hospital and Emergency hospital, which are intended for accepting ambulance. However, both of hospitals are placed on the right-bank part of city that makes a long distance for cases from the left-bank part of city. It can affect on outcome of patients. Thus, the future research would include analyzing of transportation time. Moreover, we intend to study a real-time ambulance car location, because an ambulance car can accept the call on the road.

\section{Conclusion}

GIS tools are useful tool that can be implemented in planning of emergency medical service. In our study, we determined that the service areas of ambulance stations cover the needs of patients with ACS. But nevertheless, it is necessary to plan the ambulance care to nearby regions and villages. In addition, it needs to consider the development of new areas of city and patterns of emergency calls in planning.

\section{Limitations}

Missing values (NA's) and not correct coded data in ambulance database do not give a complete picture of descriptive analysis. The lack of data on the geographical distribution of the population did not allow us to standardize the indicator of the kernel density of ACS per 10,000 population. Missing values in the mileage and incorrect time values did not allow us to calculate the average speed for an emergency call. For this reason, the service areas were calculated with crude approximated by an average ambulance speed of $50 \mathrm{~km} / \mathrm{h}$.

\section{Acknowledgments}

Our gratitude to Semey Medical University and Semey ambulance service. The study was carried out in the framework of Semey Medical University grant financing. Also, the authors would like to acknowledge the project Tutorial of Erasmus+programme for funding access to ArcGIS products.

\section{Disclaimer}

Any opinions and views represented in the article belong to the authors and represent authors' views, and do not represent any institutions, organization, or funders. 


\section{References}

1. Roth GA, Abate D, Abate KH, Abay SM, Abbafati C, Abbasi N, et al. Global, regional, and national age-sex-specific mortality for 282 causes of death in 195 countries and territories, 19802017: A systematic analysis for the global burden of disease Study 2017. Lancet. 2018;392(10159):1736-88.

PMid:30496103

2. Мединформ. Available from: http://www.medinfo.kz/\#/dpsobl. [Last accessed on 2020 Jun 21].

3. O'Gara PT, Kushner FG, Ascheim DD, Casey DE, Chung MK, de Lemos JA, et al. 2013 ACCF/AHA guideline for the management of ST-elevation myocardial infarction: A report of the American college of cardiology foundation/American heart association task force on practice guidelines. J Am Coll Cardiol. 2013;61(4):e78-140. https://doi.org/10.1002/ccd.24776 PMid:23256914

4. Golden AP, Odoi A. Emergency medical services transport delays for suspected stroke and myocardial infarction patients. BMC Emerg Med. 2015;15:34. https://doi.org/10.1186/ s12873-015-0060-3

PMid:26634914

5. Chen XQ, Liu ZF, Zhong SK, Niu XT, Huang YX, Zhang LL. Factors influencing the emergency medical service response time for cardiovascular disease in Guangzhou, China. Curr Med Sci. 2019;39(3):463-71. https://doi.org/10.1007/ s11596-019-2061-z

PMid:31209820

6. Lam SS, Nguyen FN, Ng YY, Lee VP, Wong TH, FookChong SM, et al. Factors affecting the ambulance response times of trauma incidents in Singapore. Accid Anal Prev. 2015;82:27-35. https://doi.org/10.1016/j.aap.2015.05.007

PMid:26026970

7. Nehme Z, Andrew E, Smith K. Factors influencing the timeliness of emergency medical service response to time critical emergencies. Prehosp Emerg Care. 2016;20(6):783-91. https:// doi.org/10.3109/10903127.2016.1164776

PMid:27487018

8. Jäger B, Haller PM, Piackova E, Kaff A, Christ G, Schreiber W, et al. Predictors of transportation delay in patients with suspected ST-elevation-myocardial infarction in the VIENNASTEMI network. Clin Res Cardiol. 2020;109(3):393-9. https:// doi.org/10.1007/s00392-019-01520-z

PMid:31256260

9. Namayande MS, Nejadkoorki F, Namayande SM, Dehghan H. Spatial hotspot analysis of acute myocardial infarction events in an urban population: A correlation study of health problems and industrial installation. Iran J Public Health. 2016;45(1):94-101. PMid:27057527

10. Kjærulff TM, Ersbøll AK, Gislason G, Schipperijn J. Geographical clustering of incident acute myocardial infarction in Denmark: A spatial analysis approach. Spat Spatiotemporal Epidemiol. 2016;19:46-59. https://doi.org/10.1016/j.sste.2016.05.001 PMid:27839580

11. Patel $A B$, Waters NM, Ghali WA. Determining geographic areas and populations with timely access to cardiac catheterization facilities for acute myocardial infarction care in Alberta, Canada. Int J Health Geogr. 2007;6:47. https://doi. org/10.1186/1476-072x-6-47

PMid: 17939870

12. Timonin S, Kontsevaya A, McKee M, Leon DA. Reducing geographic inequalities in access times for acute treatment of myocardial infarction in a large country: The example of Russia. Int J Epidemiol. 2018;47(5):1594-602. https://doi.org/10.1093/

\section{ije/dyy 146}

PMid:30085113

13. Stassen $W$, Olsson L, Kurland L. The application of optimisation modelling and geospatial analysis to propose a coronary care network model for patients with ST-elevation myocardial infarction. Afr J Emerg Med 2020. https://doi.org/10.1016/j. afjem.2020.04.008

14. Peters J, Hall GB. Assessment of ambulance response performance using a geographic information system. Soc Sci Med. 1999;49(11):1551-66. https://doi.org/10.1016/ s0277-9536(99)00248-8

PMid:10515636

15. Jagtenberg CJ, Bhulai S, van der Mei RD. Dynamic ambulance dispatching: is the closest-idle policy always optimal? Health Care Manag Sci. 2017;20(4):517-31. https://doi.org/10.1007/ s10729-016-9368-0 PMid:27206518

16. Coskun N, Erol R. An optimization model for locating and sizing emergency medical service stations. J Med Syst. 2010;34(1):439. https://doi.org/10.1007/s10916-008-9214-0 PMid:20192054

17. Bianchi G, Church RL. A hybrid FLEET model for emergency medical service system design. Soc Sci Med. 1988;26(1):163-71.

18. Halseth G, Rosenberg MW. Locating emergency medical services in small town and rural settings. Socioecon Plann Sci. 1991;25(4):295-304. https://doi. org/10.1016/0038-0121(91)90004-b

PMid: 10116440

19. Sasaki S, Comber AJ, Suzuki H, Brunsdon C. Using genetic algorithms to optimise current and future health planning the example of ambulance locations. Int $\mathrm{J}$ Health Geogr. 2010;9(1):4. https://doi.org/10.1186/1476-072x-9-4 PMid:20109172

20. Christensen EF, Bendtsen MD, Larsen TM, Jensen FB, Lindskou TA, Holdgaard $\mathrm{HO}$, et al. Trends in diagnostic patterns and mortality in emergency ambulance service patients in 2007 2014: A population-based cohort study from the North Denmark Region. BMJ Open. 2017;7(8):e014508. https://doi.org/10.1136/ bmjopen-2016-014508

PMid:28827233

21. Lowthian JA, Jolley DJ, Curtis AJ, Currell A, Cameron PA Stoelwinder JU, et al. The challenges of population ageing: Accelerating demand for emergency ambulance services by older patients, 1995-2015. Med J Aust. 2011;194(11):574-8. https://doi.org/10.5694/j.1326-5377.2011.tb03107.x

PMid:21644869

22. Veser A, Sieber F, Groß S, Prückner S. The demographic impact on the demand for emergency medical services in the urban and rural regions of Bavaria, 2012-2032. Z Gesundh Wiss. 2015;23(4):181-8. https://doi.org/10.1007/s10389-015-0675-6 PMid:26191488

23. Jones $M$, Chanturidze $T$, Franzen $S$, Manu A, Naylor M. Specifying a state guaranteed health benefits package for Kazakhstan: Lessons for emerging economies and middleincome countries. Int J Health Plann Manage. 2017;32(4):54053. https://doi.org/10.1002/hpm.2359 PMid:28078799

24. Glonti K. Specialized and inpatient services. In: Trends in Health Systems in the Former Soviet Countries. Brussels, Belgium: European Observatory on Health Systems and Policies; 2014.

25. Katsaga A, Kulzhanov M, Karanikolos M, Rechel B. Kazakhkstan health system review. Health Syst Transit. 2012;14(4):1-154. PMid:22894852

26. История-Скорая помощь г. Семей. Available from: http:// 
www.103semey.kz/o-nas/istoriya.html. [Last accessed on 2020 Aug 12].

27. Terzi O, Sisman A, Canbaz S, Dündar C, Peksen Y. A geographic information system-based analysis of ambulance station coverage area in Samsun, Turkey. Singapore Med J. 2013;54(11):653-8. https://doi.org/10.11622/smedj.2013228 PMid:24276104

28. Gonzalez RP, Cummings GR, Harlan SM, Mulekar MS, Rodning CB. EMS Relocation in a rural area using a geographic information system can improve response time to motor vehicle crashes. J Trauma. 2011;71(4):1023-6. https://doi.org/10.1097/ ta.0b013e318230f6f0

PMid:21986742

29. Dibene JC, Maldonado Y, Vera C, de Oliveira M, Trujillo L,
Schütze O. Optimizing the location of ambulances in Tijuana, Mexico. Comput Biol Med. 2017;80:107-15. https://doi. org/10.1016/j.compbiomed.2016.11.016

PMid:27930929

30. Chen A, Lu TY, Ma M, Sun WZ. Demand forecast using data analytics for the preallocation of ambulances. IEEE J Biomed Health Inform. 2016;20(4):1178-87. https://doi.org/10.1109/ jbhi.2015.2443799

31. Chase D, Roderick P, Cooper K, Davies R, Quinn T, Raftery J. Using simulation to estimate the cost effectiveness of improving ambulance and thrombolysis response times after myocardial infarction. Emerg Med J. 2006;23(1):67-72. https://doi. org/10.1136/emj.2004.023036

PMid:16381082 